\title{
Percutaneous cannulation of the internal jugular vein
}

\author{
I. C. W. ENGLISH, R.M. FREW, J.F.G. PIGOT T, \\ A N D M. Z AKI
}

From the Department of Anaesthetics, Brompton Hospital, London

\begin{abstract}
Two simple techniques for central venous cannulation by percutaneous puncture of the right internal jugular vein are described. They have been employed routinely for the last six months in all patients requiring central venous cannulation. No serious complications or difficulties have been encountered in a series of two hundred cases. The method allows free movement of the limbs postoperatively and avoids the painful thrombotic sequelae associated with the use of superficial veins for long-term cannulation.
\end{abstract}

Central venous cannulation is necessary to measure central venous pressure or to obtain samples of mixed venous blood. It also provides a suitable channel for rapid intravenous transfusion. The indications for its use include major cardiac and vascular surgery, hypovolaemic shock, cardiac failure, and cardiac arrest. With growing recognition of the value of central venous pressure measurements, the number of such cannulations performed has increased rapidly.

The original techniques employed involved cutting down on the saphenous or brachial veins and advancing long cannulae into the inferior or superior venae cavae. These procedures were time-consuming and resulted in a high incidence of thrombotic complications. For these reasons cannulation of the inferior vena cava became unpopular. Attention turned to more direct approaches to the superior vena cava. The external jugular vein was used, and percutaneous cannulation of the subslavian vein by infra- and supraclavicular routes was described (Yoffa, 1965; Davidson, Ben-Hur, and Nathen, 1963). Cannulation of the subclavian vein proved to be relatively easy, but accidental puncture of the pleura occurred not infrequently, with occasional fatal consequences (Schapira and Stern, 1967). The external jugular was used with success, but the anatomy is variable and in many instances it is impossible to advance the cannula into the superior vena cava (Craig, Jones, Sproul, and Kinyon, 1968). Also, in our experience, thrombotic complications are common and discomfort made the technique less acceptable to patients. Many of the patients operated on in this hospital require central venous cannulation, and for the last six months percutaneous cannulation of the right internal jugular has been used routinely. An alternative technique, described below, has beeno used in patients who suffered cardiac arrest and in those instances where the internal jugular veino was impalpable.

\section{ANATOMY}

The internal jugular vein emerges from the base of the skull posterior to the internal carotid artery ancB is included loosely in the carotid sheath. As it descendsthrough the neck it becomes lateral and finally antero을 lateral to the internal and common carotid arteries. I is crossed superficially by the posterior belly of the digastric, and by the omohyoid muscle. Throughout most of its course it is overlapped by the sterno $x$ mastoid; the nerves and vessels to the sternomastoiof also cross the vein. The vein ends behind the media $\vec{b}$. edge of the clavicular head of the sternomastoid jus? above the medial end of the clavicle; this is the mosk important surface marking. The vein is deep to the deep cervical fascia. Tributaries from the anterion jugular vein pass through the gap between the two heads of sternomastoid. The thoracic duct on the lef and the right lymphatic duct enter the confluence of the internal jugular and subclavian veins posteriorly N The right side is preferred for cannulation, as tho internal jugular and innominate veins and superior vena cava are almost in a straight line.

\section{TECHNIQUES}

Two techniques were used-an elective technique and an alternative technique.

ELECTIVE TECHNIQUE With the patient anaesthetized and intubated, the table is tilted 20 degrees head downo and the patient's head is turned to the left. With muscular relaxation and the raised jugular venous pres-O 
sure the vein is usually palpable and can be distinguished easily from the carotid artery. Eight-inch Bardic Intracaths are used, size 16/14 (large) for adults and most children, and size 16/17 (medium) for neonates and small children. The needle is inserted at an angle of about 40 degrees to the skin at a point where the vein is easily palpable. The needle is advanced posteriorly laterally and caudally through the deep cervical fascia into the vein. Passage through the fascia and vein wall is accompanied by a definite click. A reflux of venous blood confirms the venepuncture. The catheter is threaded down the needle and the needle is withdrawn. The needle is replaced in its plastic holder and a folded swab is applied firmly to the puncture site with Elastoplast to prevent haematoma formation.

ALTERNATIVE TECHNIQUE When the internal jugular vein cannot be felt or the elective technique fails, a lower approach can be used. Also it is of use in cases of cardiac arrest and other emergencies, or in conscious patients where relaxation of the sternomastoid is not sufficient to allow the vein to be felt easily.

A head down tilt is used to ensure that there is a positive venous pressure and the patient's head is turned to the left. The gap between the two heads of sternomastoid can be felt and the end of the internal jugular lies behind the medial border of the clavicular head of the muscle above the anterior end of the first rib. The needle is inserted near the apex of the triangle between the two heads of sternomastoid; it is angled 30 degrees posteriorly and advanced caudally and slightly laterally towards the anterior end of the first rib. The lower end of the internal jugular or the innominate vein is entered behind the medial end of the clavicle. The catheter is threaded down the needle and secured, as already described.

Possible complications with the first technique are few: the only structures likely to be encountered are the omohyoid and the carotid artery. The latter can be avoided if its position is located beforehand. With the second technique, the anterior jugular may be entered, into which the cannula cannot be threaded. The brachial plexus and subclavian artery are behind the scalenus anterior. The cervical pleura is posterior to the line of advance of the needle. Great care must be taken to ensure that there is a positive venous pressure if air embolism is to be avoided. The left side should not be used because of risk of damage to the thoracic duct.
RESULTS

Two hundred cannulations have been performed. The cases were unselected and all members of the anaesthetic department took part in the trial.

The results are set out in Table I. There were 13 failures, $6.5 \%$; the failure rate declined from $8 \%$ in the first hundred to $5 \%$ in the second hundred. The causes of failure are set out in Table II. None of the haematomata was serious or

T A B L E I

\begin{tabular}{c|r|c|c|c|c}
\hline $\begin{array}{c}\text { Age } \\
\text { Group } \\
\text { (yrs) }\end{array}$ & No. & Palpable & \multicolumn{2}{|c|}{ Internal Jugular Vein } & Failure \\
\cline { 3 - 5 } & & $\begin{array}{c}\text { Impalp- } \\
\text { able }\end{array}$ & Success & \\
\hline $0-1$ & 1 & 0 & 1 & 1 & 0 \\
$1-5$ & 9 & 4 & 5 & 7 & 2 \\
$5-15$ & 24 & 19 & 5 & 22 & 2 \\
Over 15 & 166 & 129 & 37 & 157 & 9 \\
\hline Total & 200 & $152(76 \%)$ & $48(24 \%)$ & $187(93.5 \%)$ & $13(6.5 \%)$ \\
\hline
\end{tabular}

T A B L E I I

REASONS FOR FAILURE

\begin{tabular}{|c|c|c|c|c|}
\hline Reason & & No. & $\begin{array}{c}\text { Haematoma } \\
\text { Formation }\end{array}$ & $\begin{array}{c}\text { Impalpable } \\
\text { Internal } \\
\text { Jugular Vein }\end{array}$ \\
\hline $\begin{array}{l}\text { Failed to thread } \\
\text { ? Arterial puncture } \\
\text { Anticoagulants } \\
\text { Obesity }++\quad \ldots \\
\text { Acromegaly } \quad \ldots \\
\text { ? In tissues } \quad \ldots\end{array}$ & $\begin{array}{l}\cdots \\
\cdots \\
\cdots \\
\cdots \\
\cdots\end{array}$ & $\begin{array}{l}6 \\
3 \\
1 \\
1 \\
1 \\
1\end{array}$ & $\begin{array}{l}1 \\
3 \\
1 \\
0 \\
0 \\
0\end{array}$ & $\begin{array}{l}1 \\
1 \\
1 \\
1 \\
1 \\
0\end{array}$ \\
\hline
\end{tabular}

required treatment. One catheter turned back into the subclavian vein; the remainder advanced into the superior vena cava, their position being confirmed by post-operative radiographs. All the catheters remained patent for as long as was required. No thrombotic complications were observed. Patients have found the catheters acceptable and compatible with free movement of the neck.

\section{REFERENCES}

Craig, R. G., Jones, R. A., Sproul, G. J., and Kinyon, G. E. (1968). The alternate methods of central venous system catheterization. Amer. Surgn, 34, 131.

Davidson, J. T., Ben-Hur, N., and Nathen, H. (1963). Subclavian venepuncture. Lancet, 2, 1139.

Schapira, M., and Stern, W. Z. (1967). Hazards of subclavian vein cannulation for central venous pressure monitoring. J. Amer. med. Ass., 201, 327.

Yoffa, D. (1965). Supraclavicular subclavian venepuncture and catheterisation. Lancet, $2,614$. 